\title{
O trabalho dos agentes de trânsito do município de São Paulo: uma análise ergonômica*
}

\author{
The work of traffic agents in São Paulo: \\ an ergonomics analysis
}

\author{
Rita Maria de Abreu Gonçalves ${ }^{1}$,Selma Lancman², \\ Tatiana Andrade Jardim ${ }^{3}$, Laerte Idal Sznelwar ${ }^{4}$, Louis Trudel ${ }^{5}$
}

GONÇALVES, R. M. A.; LANCMAN, S.; JARDIM, T. A.; SZNELWAR, L. I.; TRUDEL, L. O trabalho dos agentes de trânsito do Município de São Paulo: uma análise ergonômica. Rev. Ter. Ocup. Univ. São Paulo, v. 16, n. 2, p. 82-89, maio./ago., 2005.

\begin{abstract}
RESUMO: Objetivo: Analisar diferentes aspectos do trabalho dos agentes de trânsito, colaborando na identificação de fatores geradores de adoecimento, absenteísmo, e aposentadorias precoces e propor alternativas à execução desse trabalho; contribuir na compreensão da relação desgaste e envelhecimento precoce no trabalho e fazer avançar a prática da terapia ocupacional no estudo de situações de trabalho. Metodologia: Análise ergonômica do trabalho (AET) composta das seguintes etapas: análise da demanda e sua reformulação; levantamento e análise de dados de saúde e recursos humanos; escolha e estudo aprofundado de uma situação de trabalho, análise da atividade; formulação e validação de hipóteses; diagnóstico e recomendações. Resultados: Há grande variabilidade das tarefas realizadas numa mesma área e entre regiões; são realizadas muitas tarefas não prescritas, algumas são estratégias operatórias para atenuar a violência a que os agentes estão expostos, como: agressões físicas, verbais e conflitos com os usuários; as comunicações realizadas com a clientela extrapolam a orientação; há desgaste físico pelas tarefas serem realizadas em pé, em deambulação e com adoção de posturas desconfortáveis; a experiência adquirida é fundamental para cumprir a produtividade exigida. Discussão: A exposição diária e solitária a diversos fatores de desgaste como situações de violência; exigência de alto índice de produtividade, falta de treinamento e reciclagem são alguns fatores que podem estar causando adoecimentos físico e mental. Conclusão: os terapeutas ocupacionais em parceria com equipes multiprofissionais ao fazerem uso da AET podem conhecer melhor aspectos do trabalho, propor soluções de caráter preventivo e fazer avançar o campo da saúde e trabalho.
\end{abstract}

DESCRITORES: Terapia ocupacional/tendências. Engenharia humana/normas. Saúde ocupacional. Saúde mental. Trabalho. Ambiente de trabalho.

\footnotetext{
* Este artigo é uma síntese da Análise Ergonômica do Trabalho que integra o relatório da pesquisa: Sofrimento psíquico e envelhecimento no trabalho: um estudo com agentes de trânsito na Companhia de Engenharia de Tráfego na cidade de São Paulo: contribuições da terapia ocupacional na prevenção de adoecimentos, afastamentos e aposentadoria precoce, realizado pelo Laboratório de Investigação e Intervenção em Saúde e Trabalho - LIIST da FMUSP (CNPq processo nº 473880/2003).

${ }^{1}$ Terapeuta Ocupacional do Centro de Referência em Saúde do Trabalhador da Mooca - Secretaria Municipal da Saúde/ PMSP, Especialista em Saúde Mental e em Ergonomia pela POLI/USP.

${ }^{2}$ Professora Livre-Docente do Curso de Terapia Ocupacional da FMUSP.

${ }^{3}$ Terapeuta ocupacional, mestranda do Programa de Ciências da Reabilitação/FMUSP.

${ }^{4}$ Professor Doutor do Departamento de Engenharia de Produção da Escola Politécnica da USP.

${ }^{5}$ Professeur titualire Département de Réadaptation de 1’Université de Laval, Québec, Canadá.

Endereço para correspondência: ritaabreu@ig.com.br
} 


\section{INTRODUÇÃO}

A $\mathrm{s}$ diversas mudanças que têm ocorrido no mundo do trabalho têm gerado novos desafios para os estudiosos e profissionais que buscam compreender e diminuir o impacto dessas mudanças na saúde dos trabalhadores. Para tanto é necessário somar olhares e disciplinas que possam contribuir em intervenções mais globais dirigidas a fatores organizacionais, políticos, econômicos e culturais, entre outros (WATANABE; GONÇALVES, 2004).

Nos últimos anos os terapeutas ocupacionais que atuam na área de saúde e trabalho, em consonância com outros profissionais da área, têm buscado congregar abordagens teóricas e metodológicas a fim de ampliar sua atuação, anteriormente dirigida à reabilitação e a readaptação profissional, para a prevenção de processos de adoecimento, estudo e transformação de situações de trabalho. Disciplinas como a ergonomia e a psicodinâmica do trabalho começam a serem apreendidas e aplicadas por esses profissionais no sentido de somar conhecimentos, aumentar o espectro dos estudos e intervenções.

Os terapeutas ocupacionais, ao se apropriarem dessas disciplinas para a compreensão das relações entre saúde e trabalho, estudam e analisam as condições e a organização do mesmo e os aspectos relacionados às estratégias individuais e coletivas utilizadas pelos trabalhadores para realizar suas atividades frente às contradições do trabalho na atualidade. Buscam formular proposições e soluções junto aos trabalhadores que garantam tanto a preservação da saúde quanto a melhoria da produção. Estas novas abordagens também têm subsidiado as ações dos terapeutas ocupacionais em programas de retorno e reintegração de trabalhadores afastados por doenças ou acidentes relacionados ao trabalho evitando os processos de exclusão e de aposentadoria precoce.

Este artigo é fruto de uma pesquisa realizada na Companhia de Engenharia de Tráfego (CET) da cidade de São Paulo com agentes de fiscalização do Estacionamento Rotativo, setor conhecido como Zona Azul. O estudo foi iniciado a partir de uma demanda da empresa, preocupada com os agravos da saúde, com o aumento dos índices de afastamento, absenteísmo no trabalho e com o processo de sofrimento psíquico e envelhecimento precoce no trabalho vivenciado pelos agentes e foi realizado pelo Laboratório de Investigação e Intervenção em Saúde e Trabalho (LIIST) do Departamento de Fisioterapia, Fonoaudiologia e Terapia Ocupacional da FMUSP em parceria com Departamento de Engenharia de Produção da Escola Politécnica da USP com apoio financeiro do CNPq.
Os agentes da CET, apesar de pertencerem ao setor formal de trabalho e possuírem vínculo empregatício mais estável, próprio do setor de serviços públicos, têm passado por vários processos de deterioração das condições de trabalho. Entre estes processos, destacamos as dificuldades pelas quais os serviços públicos vêm passando e o fato dos trabalhadores serem responsabilizados pelos munícipes pelas inoperâncias dos serviços e pela crise da instituição pública que representam.

Embora a produtividade esperada no setor público não seja comparável à do setor privado, as mesmas lógicas organizacionais utilizadas pelas empresas privadas têm sido aplicadas às instituições prestadoras de serviços públicos, sobretudo no que diz respeito ao enxugamento de efetivos e à implantação de metas de produção. Como consequiência, tem havido, em muitas situações, sobrecarga de trabalho para os que permanecem agravada pela falta de inovação tecnológica para suprir uma demanda cada vez maior.

Os profissionais do setor público estão expostos, ainda, a outras formas de instabilidade e precarização, tais como: oscilações políticas e de planejamento que geram descontinuidade de projetos em curso, achatamento salarial e perda de direitos trabalhistas, acúmulo de funções e mudanças na organização do trabalho ou na natureza das ações que desenvolvem.

A presente pesquisa objetivou compreender as condições e a organização do trabalho a partir da análise da atividade e do conhecimento que os agentes de trânsito têm sobre o próprio processo de trabalho. Buscávamos dar visibilidade a aspectos do trabalho por vezes desconhecidos, como a variabilidade das tarefas realizadas, as tarefas não prescritas, a regulação de incidentes, as estratégias operatórias utilizadas, a forma como o trabalhador utiliza seu corpo, seu saber e sua experiência para desenvolver o trabalho e, ainda, propor recomendações que pudessem subsidiar a empresa em processos de mudanças neste trabalho.

Era nosso objetivo, ainda, compreender aspectos relacionados a esse trabalho que pudessem ser generalizáveis para outros contextos e situações, contribuindo assim para o desenvolvimento teórico do campo e para a compreensão da relação entre trabalho, adoecimentos, sofrimento psíquico, desgaste e envelhecimento precoce no trabalho.

\section{MATERIALEMÉTODOSUTILIZADOS}

Para a realização do estudo foram utilizadas duas abordagens teórico-metodológicas distintas: a ergonomia e a psicodinâmica do trabalho. Devido à quantidade de informações obtidas, o presente artigo focará os resultados obtidos a partir da Análise Ergonômica do Trabalho (AET). 
Segundo Wisner (1972) a ergonomia é a articulação de conhecimentos científicos relativos ao homem, necessários para conceber ferramentas, máquinas e dispositivos que possam ser utilizados por um maior número de pessoas; sendo seu objetivo primordial adaptar todo e qualquer trabalho ao homem, buscando garantir a saúde dos trabalhadores com o máximo de conforto, segurança e eficácia.

A análise e intervenção ergonômica se estruturam a partir de um amplo e diversificado levantamento de dados e informações que dizem respeito ao trabalho a ser analisado. Para tanto, utiliza várias fontes para coleta de informações: documentos fornecidos pela empresa; entrevistas com diversos níveis hierárquicos; questionários; observações abertas e sistemáticas; filmagem e fotos da atividade de trabalho. Todo o material coletado foi analisado e organizado sob a forma de um relatório, apresentado aos trabalhadores para que estes pudessem validá-lo ou refutá-lo. Após a validação foram propostas recomendações que poderão subsidiar a Empresa em processos de mudanças.

Metodologicamente foram seguidas as seguintes etapas propostas pela AET: análise da demanda e sua reformulação; levantamento e análise de dados de diferentes fontes; escolha de uma situação / posto de trabalho a ser estudado; estudo aprofundado da situação de trabalho escolhida, análise da atividade realizada; formulação de hipóteses e validação das mesmas; diagnóstico e recomendações.

\section{CARACTERÍSTICASGERAISDAEMPRESAEDAZONA AZUL}

\section{A Companhia de Engenharia de Tráfego}

A Companhia de Engenharia de Tráfego (CET), uma empresa de economia mista vinculada ao município de São Paulo, é responsável pela implantação, operação e sinalização do sistema viário, pelo desenvolvimento de estudos e projetos visando a racionalização das condições de segurança e fluidez, pelo desenvolvimento de novas tecnologias e administração do Estacionamento Rotativo nas ruas da cidade, popularmente conhecido como Zona Azul (ZA).

A ZA foi criada em 1974, visando a racionalização do uso das vagas de estacionamento nas ruas da cidade.

Essa pesquisa foi iniciada em 2003 e na defasagem de tempo entre a demanda e a obtenção de recursos para realizá-la (financiamento $\mathrm{CNPq}$ ) ocorreu uma importante mudança no setor com a proposta de privatização e a desativação da Zona Azul e a transferência de $70 \%$ dos agentes para outras funções. Os demais trabalhadores, no período em que a pesquisa de campo foi realizada, em 2004, aguardavam uma definição da CET quanto a prazos e ao seu destino e terminaram por acumular funções antes divididas entre um número maior de trabalhadores.

Cabe destacar que após o término da pesquisa e com a mudança de administração municipal, o processo de extinção da Zona Azul foi interrompido e revertido. Assim, alguns resultados dessa investigação têm subsidiado a empresa na re-estruturação da função.

\section{As equipes fixas e seu trabalho}

O início da análise ergonômica se caracterizou pela aplicação de entrevistas com trabalhadores dos diversos níveis hierárquicos que compõem a Zona Azul. Verificamos que o trabalho realizado pelas equipes fixas envolvia a maior parte dos agentes e que estes trabalhavam sozinhos em determinadas áreas pré-definidas pelas chefias.

O trabalho na Zona Azul sofreu diversas mudanças ao longo dos anos com a incorporação de novas tarefas, entre elas, a venda de talões que tornou os agentes alvo de assaltos e as autuações que geraram conflitos com os munícipes, expondo-os a agressões. O contato com situações de violência, sobretudo por trabalharem sozinhos, tem aumentado as vivências de medo, as situações de fadiga e desgaste psíquico,

Outra fonte de conflitos é a convivência com outros atores que ocupam e disputam os espaços urbanos, tais como: camelôs, cambistas e guardadores de vagas. Algumas regiões são reconhecidas como violentas pelos elevados índices de periculosidade que apresentam devido ao intenso movimento e presença ostensiva destes munícipes. Para lidarem com tais constrangimentos, estabelecem uma rede social de referência e apoio na área em que trabalham.

Um outro aspecto importante é o fato da produção ser calculada sobre o número de vagas a serem fiscalizadas, sem considerar que em algumas regiões onde há um maior número de garagens, a distância entre cada uma delas é maior e, em outras, a rotatividade de veículos é maior. $\mathrm{O}$ cálculo de produtividade também não leva em conta a variação dos dias e horários na demanda de estacionamento e o fato dos agentes trabalharem toda jornada em pé e deambulando, o que ocasiona grande desgaste físico.

\section{Características da população trabalhadora}

O estacionamento rotativo já foi composto de 940 agentes de fiscalização na década de 1990 , sofrendo gradativa diminuição devido a aposentadorias, 
adoecimentos e não reposição de trabalhadores. O número de agentes caiu para $170 \mathrm{em} 2004$ com a transferência de grande parte do contingente para a operação. Estes trabalhadores, a maioria mulheres (88\%), com idade entre 41 e 60 anos (74\%), possuem ensino médio completo (71\%) e trabalham a mais de 10 anos na empresa e no cargo (79\%).

A jornada de trabalho é de 36 horas semanais, incluindo sábados, com 15 minutos de pausa e, em geral, não realizavam hora-extra.

Em 2003 foram registrados 49 acidentes de trabalho sendo que destes, 29 foram registrados como acidentes de trabalho típico, 13 como acidentes de trajeto e 7 notificações de doença ocupacional. Vale destacar que $94 \%$ dos acidentes determinaram afastamentos do trabalho' ${ }^{1}$. Com relação às patologias descritas nas $\mathrm{CATs}^{2}$ destacamos que $55 \%$ foram por entorses, fraturas e contusões; $21 \%$ por patologias relacionadas a distúrbios psíquicos e $12 \%$ por problemas relacionados ao sistema músculo-esquelético.

Em referência aos dados dos 20 questionários ${ }^{3}$ respondidos pelos agentes, observamos que $65 \%$ dos trabalhadores apresentaram queixas, que podiam ou não se caracterizar como patologias. Destas, $38 \%$ referiam-se a problemas articulares e reumatológicos, $24 \%$ a problemas osteo-musculares, $17 \%$ a queixas psicofisiológicas e $21 \%$ a outras queixas. Salientamos que alguns trabalhadores referiram mais de uma queixa ou patologia.

Ao compararmos os dados de saúde encontrados nas CATs e nos questionários pudemos verificar que as queixas ou patologias psicofisiológicas são proporcionalmente coincidentes ( $21 \%$ e $17 \%$ respectivamente). Se agruparmos as patologias músculo-esqueléticas (tendinites, bursites e lombalgias), observamos que estas equivalem a $12 \%$ do total, ocupando lugar de destaque nos motivos de afastamentos entre esses trabalhadores ( $3^{\mathrm{a}}$ causa de afastamento). Os casos de entorse, contusões e fraturas (55\%) presentes nas CATs possivelmente estão relacionados a acidentes de trabalho típicos devido à má conservação das calçadas e vias públicas.

Com relação à produtividade, em 2004, os 170 agentes deveriam fiscalizar as 32.000 vagas existentes. Cada grupo de 6 a 8 agentes era responsável por um setor (1200 a 1500 vagas), cabendo, assim, entre 200 a 300 vagas por trabalhador. Vale ressaltar o aumento desproporcional entre o número de vagas a serem fiscalizadas em contrapartida à diminuição do número de trabalhadores ao longo dos anos ${ }^{4}$.

\section{As tarefas realizadas e suas exigências}

Entre as tarefas ${ }^{5}$ realizadas destacamos as mais importantes e freqüentes no cotidiano de trabalho: fiscalização de cartão nos veículos, informações gerais e orientação à clientela sobre as regras de funcionamento da Zona Azul, venda de talonários e folhas avulsas, fornecimento de recibos, autuação, distribuição de folhetos informativos aos munícipes e participação em operações extras e eventos designados pela empresa.

Quando ocorre algum acontecimento relevante na cidade que resulte na liberação do estacionamento, os agentes de fiscalização devem permanecer em campo orientando os pedestres. Ao final da jornada devem, diariamente, preencher formulários de controle interno de talões da Zona Azul e autuações realizadas em campo.

Por se tratar de um trabalho realizado nas ruas, o trabalhador está diariamente exposto às condições climáticas e suas variações, mudanças de temperatura e ventilação (calor, frio, rajadas de vento, chuvas), condições de luminosidade natural, bem como exposição ao ruído urbano (veículos, máquinas, barulhos da rua), além da exposição às más condições de pavimentação e preservação das ruas e calçadas da cidade.

Para a execução do trabalho são necessários alguns pré-requisitos motores, cognitivos e senso-perceptivos. Do ponto de vista cognitivo, os agentes precisam saber ler e escrever, ter habilidade de concentração e atenção relativas ao trânsito e aos pedestres, saber administrar o tempo para fiscalizar todas as vagas, utilizar memória de curta duração e visual (para realizar a leitura da placa dos carros em movimento e se necessário autuar posteriormente). Além disso, faz-se necessária a interpretação e associação de idéias (leitura da grade do cartão), raciocínio e inteligência para tomada de informações e de decisões e estabelecimento de estratégias, entre outros aspectos.

\footnotetext{
${ }^{1}$ Departamento de Segurança e Medicina do Trabalho da CET, Comunicação de Acidente de Trabalho, 2003.

${ }^{2} \mathrm{CAT}$ - documento que se refere a comunicação de acidente de trabalho.

${ }^{3}$ Os questionários distribuídos aos trabalhadores incluíam questões relacionadas às características do trabalho; aos eventos, incidentes e intercorrências; as estratégias utilizadas para lidar com os constrangimentos do trabalho e as queixas de saúde.

${ }^{4}$ Dados referentes ao número vagas a serem fiscalizadas em relação ao número de agentes: 940 agentes/17.500 vagas em $1990 ; 170$ agentes/ 32.000 vagas em 2004.

${ }^{5}$ Segundo Guerin et al. (2001) a tarefa é a prescrição do trabalho a ser realizado, engloba os objetivos, os procedimentos, instruções, meios técnicos, divisão das tarefas, as condições do ambiente de trabalho, etc; e é determinada pela empresa.
} 
Com relação aos aspectos físicos, não podem apresentar problemas de locomoção, devem possuir boa acuidade visual (leitura dos cartões), boa audição (para não sofrerem acidentes de trânsito) e boa comunicação verbal (orientação a clientes e pedestres). Destaca-se que o mau posicionamento dos cartões nos veículos, muitas vezes, obriga que sua leitura seja feita na rua, aumentando o risco de atropelamentos.

Entre as habilidades motoras necessárias, destacamos a coordenação motora fina (necessária para escrever, fornecer troco e conferir talões) e coordenação motora grossa (exigência de deambular durante toda a jornada). Com relação a senso-percepção são necessárias as funções de organização espacial (reconhecimento do percurso já realizado, leitura da grade do cartão com rápida identificação da localização do espaço destinado aos dados do veículo), organização temporal e equilíbrio (deambular, afastar-se de obstáculos e dos buracos). Cabe ressaltar que todas essas funções, apesar de aqui didaticamente separadas, tornamse, no cotidiano das atividades de trabalho, interdependentes para o cumprimento das várias tarefas.

\section{RESULTADOS}

\section{A atividade de fiscalização}

A análise da atividade ${ }^{6}$ de fiscalização foi realizada através de observações sistemáticas, desenvolvidas em duas regiões com características bastante diversas, sendo uma eminentemente comercial e outra mista (composta por comércio, residências e escolas). Foram realizadas em diferentes horários e períodos do ano a fim de que se pudesse observar a variabilidade das tarefas e as possíveis diferenças entre as regiões, além de validar os dados anteriormente colhidos e obter novas informações sobre a atividade realizada. A partir de então, foram eleitas seis variáveis a serem observadas: ações; posturas, movimentos e deslocamentos; comunicações; incidentes eventos e intercorrências; estratégias operatórias; direção do olhar e tomada de informações.

Em relação à variabilidade das tarefas, estas mudam de acordo com as características específicas de cada região da cidade, de acordo com a sazonalidade e horário como, por exemplo, saída e entrada de escola, horário de almoço. Nas regiões comerciais observou-se maior número de infrações e, portanto, um maior índice de autuações, além de um maior número de veículos em situação irregular - sem o cartão da Zona Azul.

Outro aspecto relevante em relação às diferenças entre regiões é a variabilidade e a intensificação de um determinado tipo de tarefa em detrimento de outras. Existiam tarefas realizadas somente na região central, sendo que algumas delas não eram prescritas nem previstas na descrição do cargo e de tarefas preconizadas pela empresa.

As observações sistemáticas permitiram a visualização, no trabalhar, de ajustes e regulações que os agentes realizam para contemplar as exigências específicas da clientela e das características da área e assim poderem realizar seu trabalho. Em regiões mais conturbadas, a exposição dos agentes a agressões é maior quando precisam autuar algum munícipe, assim faz-se necessário realizar diversas tarefas não prescritas, que são estratégias desenvolvidas para evitar possíveis agressões e conflitos com a clientela e outros atores sociais: "é preciso ter estratégias para sobreviver". Estas estratégias são criadas para minimizar problemas relacionados com a organização do trabalho, com as condições ambientais, com fatores biomecânicos e, principalmente, com as relações interpessoais que se estabelecem no trabalhar na rua. A seguir destacaremos algumas destas estratégias.

Em relação ao percurso, por exemplo, realizam sempre na mesma ordem com o objetivo de ganhar tempo e dar conta da produtividade; no que se refere à verificação do cartão, fazem a leitura da data e hora primeiramente e só depois verificam os minutos, referindo gastar menos tempo na fiscalização ao focar o olhar nestes itens; em relação à resistência dos munícipes, em comprar e colocar o cartão no veículo auxiliam no preenchimento do mesmo; no que se refere à autuação, não entregam a $2^{\mathrm{a}}$ via diretamente ao munícipe, colocando-a no pára-brisa a fim de diminuir os conflitos.

Salientamos que as estratégias desenvolvidas são individuais e fruto da experiência adquirida, em consonância com as características específicas da área de trabalho, sendo que muitas delas já foram incorporadas ao coletivo dos trabalhadores.

Com relação às posturas adotadas, o trabalho em pé e a deambulação, durante toda a jornada, sobrecarregam a coluna lombar e os membros inferiores, podendo ocasionar problemas músculo-esqueléticos, articulares e vasculares.

\footnotetext{
${ }^{6}$ Segundo Guerin et al. (2001) atividade é a maneira como o trabalhador usa seu corpo e suas competências para realizar as tarefas.
} 
Na região comercial o agente adota maior número de posturas desconfortáveis dos membros superiores e coluna cervical devido a algumas ações que desenvolve com maior freqüência, tais como: escrever, vender e autuar. A realização dessas tarefas posiciona o pescoço em semiflexão, com membros superiores suspensos e sem apoio, sobrecarregando-os.

Vale ressaltar que nas duas regiões estudadas observamos dificuldades de leitura dos cartões quer por obstruções na calçada, quer pelo mau posicionamento do cartão no painel ou ainda pelo preenchimento inadequado ou altura do veículo. Estas situações obrigam o agente a adotar posturas desconfortáveis e inadequadas principalmente com o pescoço (semi-flexão e rotação lateral ou em hiper-extensão), sobrecarregando a coluna cervical,a região do trapézio e o tronco. A ocupação irregular do espaço público, por veículos transformados em lanchonetes e lojas, se configura como mais um dificultador do trabalho dos agentes.

Com relação às comunicações, observamos que estas ocorrem na maior parte da jornada: na interação com o cliente ou na demanda dos munícipes por informações gerais. Entre os processos de comunicação mais comuns, destacamos a orientação e informação sobre aspectos específicos da Zona Azul, venda de folha ou talão, solicitação de recibo, aplicação de autuação quando o condutor do veículo está presente, etc.

Verificamos ainda diversos incidentes, eventos e intercorrências principalmente entre camelôs da região comercial, tais como, recusa em colocar o cartão, uso de folha rasurada e reutilização de cartão, além de resistência do motorista em retirar o carro após vencimento do cartão.

Vale pontuar a existência de um elevado número de agressões verbais por parte dos cambistas e camelôs, principalmente na área comercial. Em 35 minutos de observação ocorreram, na região comercial, 28 intercorrências, sendo 8 com cambistas e 20 com camelôs.

$\mathrm{O}$ agente gasta em média 2 a 4 segundos para leitura do cartão. Tal agilidade é possível graças à representação mental que possuem da grade do cartão - local onde deve estar assinalado a placa do veículo, a data, o dia, o mês e o horário. Esta velocidade é influenciada por outros fatores, tais como, a acuidade visual do agente, a luminosidade, à distância entre os olhos e o cartão, as condições de visibilidade do vidro do carro e as condições de uso do cartão e seu preenchimento. Isso denota a importância da experiência, inteligência e do conhecimento adquirido pelo trabalhador.

\section{VALIDAÇÃOERECOMENDAÇÕES}

Foram produzidas algumas recomendações referentes a melhorias no trabalho, validadas pelo conjunto de trabalhadores e enviadas à empresa sob a forma de relatório. Destacamos entre elas: a importância da melhoria dos canais de comunicação entre os diversos níveis hierárquicos para que os trabalhadores possam encaminhar sugestões e reivindicações referentes à gestão de recursos humanos e a área de segurança e medicina; incorporação das sugestões dos trabalhadores relativas à organização do trabalho e a exposição e a segurança dos agentes em relação às agressões; aumento dos postos oficiais de vendas de cartões e melhoria de infra-estrutura de trabalho. Um outro aspecto importante é que a empresa invista em campanhas informativas junto aos munícipes sobre o trabalho realizado pela Zona Azul.

Entretanto para que as recomendações sejam de fato implantadas é necessário que se estabeleçam soluções de compromisso entre todos os atores sociais envolvidos no processo. Como afirma Guerin et al. (2001) toda e qualquer mudança na situação de trabalho modifica a atividade, levando os trabalhadores a utilizarem novas estratégias operatórias, que podem facilitar, mas que trazem também novas dificuldades. Assim, para que a ação ergonômica possa levar a transformações efetivas é essencial que sejam acordadas por todos os parceiros sociais.

As observações sistemáticas demonstraram que fiscalizar implica, diretamente, em estabelecer inter-relações com os diversos atores sociais que compõem o cenário das ruas da cidade. As orientações aos usuários, os vários tipos de comunicação, as estratégias operatórias para lidar com os constrangimentos diários impostos pelo trabalho compõem o trabalho real de fiscalização do estacionamento rotativo.

Segundo Montimollin (1984) a ergonomia considera como organização do trabalho o que os trabalhadores fazem, como fazem, porque fazem, em que tempo fazem e se podem fazer melhor. Desta forma desvenda aspectos do trabalho muitas vezes desconhecidos até para os próprios trabalhadores, sempre com o objetivo de adaptar o trabalho ao homem visando sua saúde e melhor produtividade. Cada trabalhador ao executar seu trabalho pode proceder de maneira diferente, dependendo do tempo que dispõe, dos instrumentos que utiliza, das condições ambientais a que está exposto, da sua experiência profissional atual e anterior, entre outras variáveis.

Os agentes estão expostos diariamente a diferentes tipos de fatores desgastantes como: o grande número de agressões verbais e físicas por parte da clientela, de camelôs, cambistas e manobristas; a insuficiência de agentes em relação ao número de vagas a serem fiscalizadas; a exigência de produtividade; os problemas relacionados ao trânsito, o aumento do número de pedestres e da frota de veículos na cidade; o desgaste 
característico de uma grande cidade como São Paulo associados à escassez de investimentos na empresa, na saúde, na capacitação e reciclagem dos funcionários.

Todos esses fatores associados às adversidades do trabalho na rua contribuíram para o desgaste, afastamento no trabalho, adoecimento físico e/ou psíquico dessa população ao longo dos anos.

\section{DISCUSSÃo}

O presente estudo mostra que os agentes realizam papel importante para a democratização do espaço público, ou seja, promovem o rodízio de vagas possibilitando que essas sejam acessadas e utilizadas por todos os munícipes. No entanto, o papel dos agentes de fiscalização da Zona Azul transcende esta função à medida que desenvolvem outras ações no cenário social: são, assim, agentes comunitários.

A AET permitiu conhecer aspectos pouco visíveis do trabalho realizado que ultrapassa a fiscalização, a venda e a autuação. A rápida leitura dos cartões nos veículos e o desenvolvimento de estratégias operatórias para lidar com os constrangimentos que ocorrem diariamente no trato com a clientela são fruto da experiência adquirida através do exercício diário do seu trabalho e acumulada ao longo dos anos. Essa experiência associada às características individuais de cada trabalhador é essencial para que o trabalho seja realizado de forma eficiente.

Durante a pesquisa de campo observou-se que, em algumas regiões, as agressões físicas e verbais e as situações de intimidação por parte da clientela são freqüentes levando o agente a situações de fadiga que podem ocasionar desgaste mental e contribuir para o adoecimento tanto físico quanto psíquico dessa população.

Como afirma Guerin et al. (2001) as relações que se estabelecem entre trabalho e saúde são complexas. As agressões à saúde do trabalhador não se expressam apenas em patologias já estabelecidas. A análise ergonômica permite identificar precocemente uma situação de trabalho que pode vir a trazer danos a saúde dos trabalhadores.

\section{CONCLUSÃO}

A prática da terapia ocupacional na área de saúde e trabalho vem se firmando e constituindo como um importante campo de atuação para estes profissionais. Nesse processo, o aditamento de novas disciplinas e metodologias teórico-práticas têm sido um fortalecedor.

Entre os vários diálogos que vêm se estabelecendo, a ergonomia tem sido de fundamental importância, em específico a ergonomia de corrente francesa e a análise ergonômica do trabalho. A AET ao estudar o homem em situação real de trabalho busca conhecer e analisar o trabalho realizado e objetiva o diagnóstico de situações que podem ocasionar, agravar ou causar adoecimentos e/ ou acidentes e, principalmente, encontrar possíveis soluções destas questões juntamente com os trabalhadores

As análises de atividades propostas pela terapia ocupacional na área de saúde e trabalho assim como pela ergonomia visam decompor a atividade de trabalho para conhecer o trabalho real, compreendê-lo e transformá-lo.

A análise da atividade de trabalho se estrutura a partir da relação que se estabelece entre o trabalhador, o trabalho, o posto de trabalho, as condições em que o indivíduo se acidentou ou adoeceu, e ainda a função para a qual será reabilitado ou readaptado.

A metodologia aqui apresentada tem colaborado também na prática desempenhada por terapeutas ocupacionais que atuam em Centros de Referência em Saúde do Trabalhador, pois tem possibilitado o conhecimento de novos elementos do trabalho que, por sua vez, ampliam as ações de vigilância á saúde dos trabalhadores.

Historicamente, o diagnóstico e análise realizados em ações de vigilância limitavam-se ao levantamento e análise de riscos, direcionando as propostas à diminuição da exposição dos trabalhadores, limitando-se aos aspectos da legislação vigente e a implantação de medidas coletivas e ao uso de equipamentos de proteção individual (EPI). Atualmente as ações de vigilância têm ultrapassado a fiscalização passando a ter um caráter educativo e, principalmente, preventivo. Assim, os terapeutas ocupacionais ao incorporarem as bases teórico-práticas da Ergonomia têm conseguido ampliar sua visão da análise da atividade de trabalho e considerar aspectos como, cargas e conforto a que o trabalhador está exposto em relação a realização do trabalho, fatores biomecânicos, fatores relacionados as condições e a organização do trabalho. Mesmo quando a análise ergonômica não pode ser realizada na sua totalidade, tal como preconizada na literatura, a identificação dos fatores ergonômicos tem possibilitado uma melhor atuação de toda a equipe multiprofissional que atua nessa área.

O incremento de pesquisas na área de saúde e trabalho só pode se dar pela congregação e combinação de esforços tanto de profissionais quanto de diferentes teorias e métodos. As pesquisas nessa área são um desafio interdisciplinar, requerem esforços múltiplos para entender a nova realidade e propõem abordagens inovadoras que possam contemplá-las em sua complexidade, além de contribuírem para o desenvolvimento de propostas de intervenção e transformação do trabalho (LANCMAN, 2004). 
GONÇALVES, R. M. A.; LANCMAN, S.; JARDIM, T. A.; SZNELWAR, L. I., TRUDEL, L. The work of traffic agents in São Paulo: an ergonomics analysis. Rev. Ter. Ocup. Univ. São Paulo, v. 16, n. 2, p. 82-89, maio./ago., 2005 .

\begin{abstract}
Objective: to analyze the various aspects of the traffic agents' job, collaborate in identify the generating hazards and risk factors of disorder, absenteeism and early retirement and propose alternatives to the execution of this job; contribute to the comprehension of the "damage $\mathrm{X}$ ageing" relation at work and rising in rank to the practice of occupational therapy in the studies of work situations. Methodology: Ergonomics Analysis of Work composed by the following steps: analysis and reformulation of the demand; survey and analysis of health and human resources data; choose and emphasize studies of a job situation, activity analysis, formulation and validation of hypothesis, diagnostic and recommendation. Results: there is a great variability of tasks accomplished within the same area and among different regions, many no prescribed tasks are accomplished, some are operational strategies to relieve the violence the traffic agents are exposed to, such as: physical and verbal aggression, conflicts with the users; the communication with the clients exceeds orientations; there is physical hazard by standing, walking and discomforting postures; the acquired experience is important for reaching the demanding productivity . Discussion: the daily and lonely exposure to several hazards and risk factors such as violence situations, high demanded levels of productivity, lack of training and recycling are some of the risk factors that may be causing physical and mental disorders. Conclusion: the occupational therapists in partnership with multidisciplinary staffs making use of Ergonomics Analysis of Work can be aware of various job aspects and suggest prevention solutions and improve field of occupational health and work.
\end{abstract}

KEY WORDS: Occupational therapy/trends. Human engineering/standards. Occupational health. Work. Mental health.

\section{REFERÊNCIAS}

GRANDJEAN, E. Manual de ergonomia - adaptando o trabalho ao homem. Porto Alegre: Bookman, 1998.

GUERÍN, F.; LAVILLE, A.; DANIELLOU, F.; DURAFFOURG, J.; KEGUELEN, A. Compreender o trabalho para transformálo: a prática da ergonomia. São Paulo: Edgard Blücher, 2001.

LANCMAN, S. (Org.). Saúde, trabalho e terapia ocupacional. São Paulo: Roca, 2004.

LANCMAN, S.; SZNELWAR, L. I.; JARDIM, T. A.; GONÇALVES, R. M. A. Sofrimento psíquico e envelhecimento no trabalho: um estudo com agentes de trânsito na Companhia de Engenharia de Tráfego na cidade de São Paulo. Relatório científico. CNPq processo no 473880/2003. (mimeo).

MONTIMOLLIN, M. L'intelligence de la tache: elementes d'ergonomie cognitive. Berna: Peter Lang, 1984.

WATANABE, M.; GONÇALVES, R. M. A. Relações conceituais entre a terapia ocupacional e a ergonomia. In: LANCMAN, S. (Org.). Saúde, trabalho e terapia ocupacional. São Paulo: Roca, 2004.

WISNER, A. A inteligência no trabalho: textos selecionados de ergonomia. São Paulo: FUNDACENTRO, 1994. 